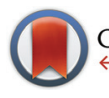

CrossMark \&lick for updates

Cite this: Dalton Trans., 2016, 45 13742

Received 22nd June 2016, Accepted 18th July 2016

DOI: $10.1039 / \mathrm{c} 6 \mathrm{dt} 02507 \mathrm{~b}$

www.rsc.org/dalton

\title{
Supramolecular adducts based on weak interactions between the trimeric Lewis acid complex (perfluoro-ortho-phenylene)mercury and polypnictogen complexes $\uparrow$
}

\author{
Martin Fleischmann, ${ }^{a}$ James S. Jones, ${ }^{\text {b }}$ Gábor Balázs, ${ }^{a}$ François P. Gabbaï*b and \\ Manfred Scheer*a
}

\begin{abstract}
Reactions of the trinuclear Lewis acid perfluoro-ortho-phenylene)mercury $\left[\left(\mathrm{O}-\mathrm{HgC}_{6} \mathrm{~F}_{4}\right)_{3}\right]$ (1) with the polypnictogen complex $\left[\mathrm{CpMo}(\mathrm{CO})_{2}\left(\eta^{3}-\mathrm{P}_{3}\right)\right](2)$ containing a cyclo- $\mathrm{P}_{3}$ ligand and the series of $\mathrm{E}_{2} \mathrm{com}-$ plexes $\left[\left\{C p M o(C O)_{2}\right\}_{2}\left(\mu, \eta^{2}: \eta^{2}-E_{2}\right)\right](E=P(3 a), A s(3 b), S b(3 c), B i(3 d))$ are reported. In all cases, the reaction products show very weak interactions between the $E_{n}$ ligand complexes and the Lewis acid 1, as evidenced by their highly dynamic behaviour in solution and the formation of adducts in the solid state showing $\mathrm{Hg} \cdots \mathrm{E}$ contacts below the respective sum of the van der Waals radii. The complexes $2\left(\mathrm{P}_{3}\right), 3 a$ $\left(\mathrm{P}_{2}\right)$ and $\mathbf{3} \mathbf{b}\left(\mathrm{As}_{2}\right)$ show interactions of only one pnictogen atom with all three $\mathrm{Hg}$ atoms of $\mathbf{1}$. The complex $3 c\left(\mathrm{Sb}_{2}\right)$ forms two adducts with 1 showing either a side-on coordination of the $\mathrm{Sb}_{2}$ dumbbell towards $\mathrm{Hg}$ or an end-on coordination of both $\mathrm{Sb}$ atoms towards two independent molecules of 1 . $\mathrm{The}^{\mathrm{Bi}} \mathrm{i}_{2}$ complex $3 \mathbf{d}$ shows an almost parallel alignment of the $\mathrm{Bi}_{2}$ dumbbell situated above the center of the planar Lewis acid 1 . The arrangements of the $E_{2}$ complex series towards 1 are rationalized with the help of electrostatic potential maps obtained by DFT calculations. Finally the structural characterizations of a new modification of the free $\mathrm{Sb}_{2}$ complex $\mathbf{3 c}$, the $\mathrm{Bi}_{2}$ complex $\mathbf{3 d}$, the starting material of its preparation $\left[\mathrm{Bi}\left\{\mathrm{CpMo}(\mathrm{CO})_{3}\right\}_{3}\right]$ (4) and an unprecedented ' $\mathrm{Cr}_{4} \mathrm{As}_{5}$ ' cluster $\mathbf{5}$ are presented.
\end{abstract}

\section{Introduction}

During the last few decades supramolecular chemistry based on weakly interacting molecules instead of strong covalent bonds has gained more and more attention. The investigation of planar electron-deficient molecules has developed into a rich area of research with applications in anion recognition, ${ }^{1,2}$ molecular machines, ${ }^{3}$ or light emitting materials. ${ }^{4}$ In this context, pyridinium cations, ${ }^{3}$ or electron deficient aromatic compounds, ${ }^{1,2}$ are prototypical representatives. We became particularly interested in the chemistry of the trinuclear organometallic compound (perfluoro-ortho-phenylene)-mercury (1). ${ }^{5}$ Due to its planar geometry this molecule contains three sterically accessi-

\footnotetext{
${ }^{a}$ Institut für Anorganische Chemie, Universität Regensburg, 93040 Regensburg, Germany. E-mail: manfred.scheer@chemie.uni-regensburg.de;

Fax: (+49) 941-943-4439

${ }^{b}$ Department of Chemistry, Texas A\&M University, College Station,

Texas 77843-3255, USA

$\dagger$ Dedicated to Professor Max Herberhold on the occasion of his $80^{\text {th }}$ birthday.

\$Electronic supplementary information (ESI) available: Details of syntheses, characterization, X-ray crystallography and DFT calculations. CCDC 1486626-1486635. For ESI and crystallographic data in CIF or other electronic format see DOI: $10.1039 / \mathrm{c} 6 \mathrm{dt} 02507 \mathrm{~b}$
}

ble mercury centers whose naturally low Lewis acidity is significantly increased by the fluorinated molecular backbone. ${ }^{6,7}$ This unusual Lewis acid builds up alternating binary stacks with aromatic hydrocarbons ${ }^{8-11}$ and forms double-sandwich complexes featuring $\mathrm{Hg} \cdot . \mathrm{Cp}$ interactions when reacted with the metallocenes $\mathrm{Cp}_{2} \mathrm{Fe}$ and $\mathrm{Cp}_{2} \mathrm{Ni}$ (Scheme 1a). ${ }^{12}$ Additionally 1 forms weak Lewis acid/base adducts with a variety of $\mathrm{O}, \mathrm{N}$ and $\mathrm{S}$ donors which simultaneously interact with all three $\mathrm{Hg}$ atoms (Scheme 1b). ${ }^{6,7,13}$ During the past few years we have extended this chemistry to polyphosphorus complexes, observing only weak $\mathrm{P} \cdots \mathrm{Hg}$ interactions instead of potential $\mathrm{Hg} \cdots \mathrm{Cp}$ interactions in the reactions of $\mathbf{1}$ and the triple-decker complex $\left[(\mathrm{CpMo})_{2}\left(\mu, \eta^{6}: \eta^{6}-\mathrm{P}_{6}\right)\right]$ (Scheme 1c). ${ }^{14}$ Recently we reported the differences in coordination behavior of the aromatic cyclo- $\mathrm{P}_{5}$ and cyclo- $\mathrm{As}_{5}$ ligands from the ferrocene analogues $\left[\mathrm{Cp}^{*} \mathrm{Fe}\left(\eta^{5}-\mathrm{E}_{5}\right)\right](\mathrm{E}=\mathrm{P}, \mathrm{As})^{15,16}$ towards the Lewis acid 1. $^{17}$ While the $\mathrm{P}_{5}$ ring forms a weak Lewis acid/base adduct (Scheme 1d) with one $\mathrm{P}$ donor atom, the $\mathrm{As}_{5}$ ring shows a rather cofacial arrangement towards the molecular plane of $\mathbf{1}$ with three As atoms interacting simultaneously with the $\mathrm{Hg}$ centers (Scheme 1e).

Since the nature of the polypnictogen complexes has been shown to have a dramatic effect on its reactivity towards $\mathbf{1}$, we 
a)

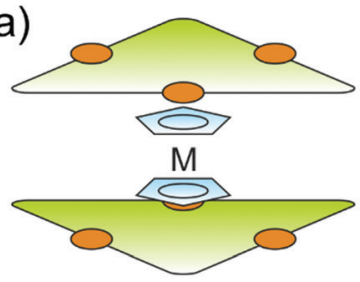

double-sandwich complexes $\mathrm{M}=\mathrm{Fe}, \mathrm{Ni}$;

b)

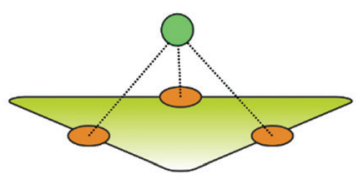

Lewis acid/base adduct c)

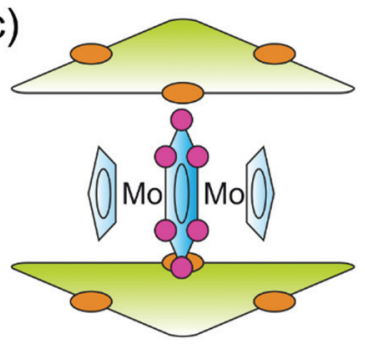

super-sandwich structure d)

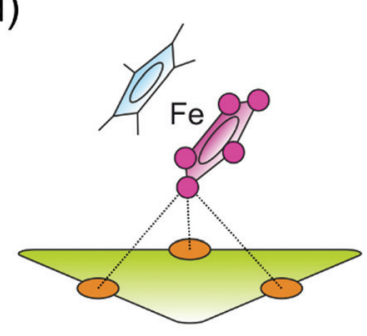

weak Hg-P adduct

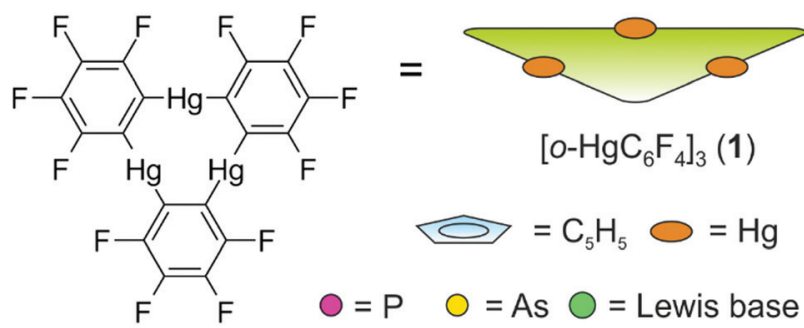

e)

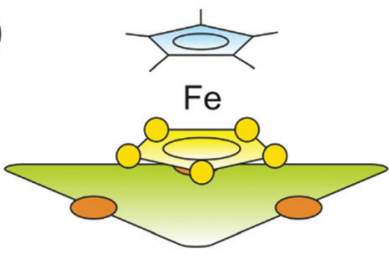

cofacial arrangement

Scheme 1 (a) Representation of the double-sandwich complexes formed from 1 and the metallocenes $\mathrm{Cp}_{2} \mathrm{Fe}$ and $\mathrm{Cp}_{2} \mathrm{Ni}$. (b) Illustration of Lewis acid/base adducts of 1 with the Lewis bases simultaneously interacting with all three $\mathrm{Hg}$ centers. (c) Super-sandwich structures obtained from 1 and $\left[(\mathrm{CpMo})\left(\mu, \eta^{6}: \eta^{6}-\mathrm{P}_{6}\right)\right]$. (d) Coordination of $\left[\mathrm{Cp} \mathrm{p}^{*} \mathrm{Fe}\left(\eta^{5}-\mathrm{P}_{5}\right)\right]$ to the three $\mathrm{Hg}$ atoms of 1 via one $\mathrm{P}$ atom. (e) $\left[\mathrm{Cp} \mathrm{p}^{*} \mathrm{Fe}\left(\eta^{5}-\mathrm{As}_{5}\right)\right]$ interacting with 1 via three As atoms showing an almost cofacial arrangement.

questioned how the trinuclear Lewis acid might interact with a terminal cyclo- $\mathrm{E}_{3}$ ligand and furthermore how its coordination behavior may vary when reacting 1 with complexes of the heavier pnictogen atoms $\mathrm{Sb}$ and $\mathrm{Bi}$. To address these questions we first investigated the reactivity of $\mathbf{1}$ towards the $\mathrm{P}_{3}$ complex $\left[\mathrm{CpMo}(\mathrm{CO})_{2}\left(\eta^{3}-\mathrm{P}_{3}\right)\right](2)$ and subsequently towards the $\mathrm{E}_{2}$ complex series $\left[\left\{\mathrm{CpMo}(\mathrm{CO})_{2}\right\}_{2}\left(\mu, \eta^{2}: \eta^{2}-\mathrm{E}_{2}\right)\right] \mathrm{E}=\mathrm{P}(\mathbf{3 a}), \mathrm{As}(\mathbf{3 b}), \mathrm{Sb}(\mathbf{3 c}), \mathrm{Bi}(\mathbf{3 d})$ (Scheme 2). For the first time the $\mathrm{Bi}_{2}$ complex $3 \mathbf{d}$ and the starting material of its synthesis $\left[\left\{\mathrm{CpMo}(\mathrm{CO})_{3}\right\}_{3} \mathrm{Bi}\right](4)$, as well as a new modification of the $\mathrm{Sb}_{2}$ complex $3 \mathrm{c}$ could be structurally characterized. Additionally, an unprecedented $\mathrm{Cr}-\mathrm{As}$ cluster $\left[(\mathrm{CpCr})_{4}\left(\mu, \eta^{3}: \eta^{3}-\mathrm{As}_{2}\right)\left(\mu, \eta^{3}: \eta^{2}: \eta^{3}-\mathrm{As}_{3}\right)\right]$ (5), obtained from a related reaction was also characterized by single crystal X-ray diffraction.

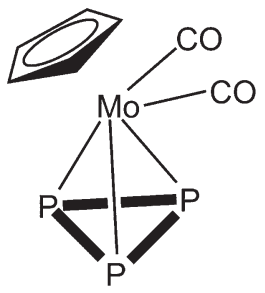

2

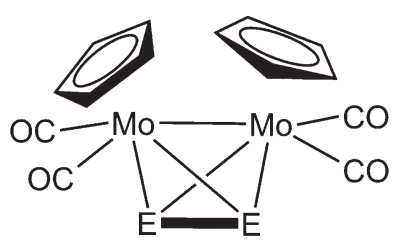

$E=P(3 a), A s(3 b), S b(3 c), B i(3 d)$
Scheme 2 Representation of the tetrahedrane complexes [CpMo $\left.(\mathrm{CO})_{2}\left(\eta^{3}-\mathrm{P}_{3}\right)\right](2)$ and $\left[\left\{\mathrm{CpMo}(\mathrm{CO})_{2}\right\}_{2}\left(\mu, \eta^{2}: \eta^{2}-E_{2}\right)\right](E=P(3 a), A s(3 b), \operatorname{Sb}(3 c)$, $\mathrm{Bi}(3 \mathrm{~d}))$.

\section{Results and discussion}

Syntheses and spectroscopic characterization of the products

The adducts between the pnictogen complexes and $\mathbf{1}$ are easily prepared by dissolving 1 and an equimolar amount of the cyclo- $\mathrm{P}_{3}$ complex 2 or the $\mathrm{E}_{2}$ complexes $3 \mathbf{a}-\mathbf{d}$ in $10 \mathrm{~mL}$ of $\mathrm{CH}_{2} \mathrm{Cl}_{2}$ until a clear solution is formed. After stirring at room temperature, this solution is filtered and the solvent is removed until the filtrate solution is saturated. Storing the resultant solutions at $+4{ }^{\circ} \mathrm{C}$ results in product crystallization in a matter of hours to days. Following this approach one can obtain pure samples of equimolar adducts of $\mathbf{1}$ and the cyclo$\mathrm{P}_{3}$ complex $2[(\mathbf{1}) \cdot(\mathbf{2})]$ ( $80 \%$ isolated yield), the $\mathrm{P}_{2}$ complex $3 \mathrm{a}$ $[(\mathbf{1}) \cdot(\mathbf{3 a})](75 \%)$ and the $\mathrm{As}_{2}$ complex $\mathbf{3 b}[(\mathbf{1}) \cdot(\mathbf{3 b})](74 \%)$, respectively. In the case of the $\mathrm{Sb}_{2}$ complex $3 \mathrm{c}$ two adducts with molar ratios of $1: 1[(\mathbf{1}) \cdot(3 \mathbf{c})]$ and $2: 1\left[(\mathbf{1})_{2} \cdot(3 \mathbf{c})\right]$ are detected from the same reaction. In the case of the $\mathrm{Bi}_{2}$ complex 3d we were able to determine the coexistence of the adduct $\left[(\mathbf{1}) \cdot(\mathbf{3 d})_{2}\right]$, pure $\mathbf{1}$ and pure $3 \mathbf{d}$ next to each other in crystalline form from the same reaction. This observation suggests very weak interactions between $\mathbf{1}$ and $\mathbf{3 d}$ and prevents a successful separation of these compounds. Moreover, the $\mathrm{Sb}_{2}$ complex 3c was isolated in 56\% yield after refluxing $\left(\mathrm{Me}_{3} \mathrm{Si}_{2} \mathrm{CHSbH}_{2}\right.$ and $\mathrm{CpMo}(\mathrm{CO})_{3} \mathrm{Me}$ in xylene for $3 \mathrm{~h}$. The reaction of the triple-decker complex $\left[(\mathrm{CpCr})_{2}\left(\mu, \eta^{5}: \eta^{5}-\mathrm{As}_{5}\right)\right]$ with 1 enabled the structural characterization of an unprecedented mixed Cr-As cluster 5 (for details see below). Since the described adducts are based on weak $\mathrm{Hg} \cdots \mathrm{E}(\mathrm{E}=\mathrm{P}, \mathrm{As}, \mathrm{Sb}, \mathrm{Bi})$ interactions we assume only very weak association in solution. 
In accordance with this, in the mass spectra we never observed any peaks assignable to any adduct but only the starting materials of the described products. The ${ }^{1} \mathrm{H}$ and the ${ }^{19} \mathrm{~F}$ NMR spectra in $\mathrm{CD}_{2} \mathrm{Cl}_{2}$ solution are unchanged compared to the starting compounds. While the ${ }^{31} \mathrm{P}\left\{{ }^{1} \mathrm{H}\right\}$ NMR spectrum of $[(1) \cdot(2)]$ in $\mathrm{CD}_{2} \mathrm{Cl}_{2}$ solution shows a sharp singlet at -349.5 ppm which is also unchanged to the starting compound 2 we can observe an upfield shift of about $11 \mathrm{ppm}$ for the singlet of the $\mathrm{P}_{2}$ ligand $3 \mathrm{a}$ in the case of the adduct $[(\mathbf{1}) \cdot(3 \mathbf{a})]$.

\section{Structural characterization of the products in the solid state}

General considerations. The solid state structures of the formed adducts exhibit short contacts below the sum of the van der Waals (vdW) radii between pnictogen atoms and the $\mathrm{Hg}$ atoms of 1 . The vdW radius of $\mathrm{Hg}$ in different compounds is discussed in the literature with reported values ranging from $1.7 \AA$ up to $2.2 \AA$. In the following discussion the shortest value of $1.7 \AA$ was taken as a reference. ${ }^{18-23}$ Therefore, $\mathrm{Hg}-\mathrm{E}$ distances that are within the sum of the vdW radii of $3.6 \AA(\mathrm{P})$, $3.7 \AA(\mathrm{As}), 3.9 \AA(\mathrm{Sb})$ or $4.1 \AA(\mathrm{Bi})$ are highlighted by fragmented orange bonds in the following Fig. 1-7.

\section{Crystal structure of the adduct [(1):(2)]}

Fig. 1 shows the solid state structure of the adduct $[(\mathbf{1}) \cdot(2)]$. Although the symmetry of the cyclo- $\mathrm{P}_{3}$ ligand of complex 2 would generally match the threefold symmetry of the planar Lewis acid 1 it shows a coordination of only one P atom interacting with all three $\mathrm{Hg}$ centers of $\mathbf{1}$. The resulting $\mathrm{Hg}-\mathrm{P}$ distances (3.19349(7)-3.25262(6) ̊) lie well within the sum of the vdW radii (3.6 $\AA$ ). These lengths are very comparable to the $\mathrm{Hg}-\mathrm{P}$ distances found for $\mathbf{1}$ and $\left[(\mathrm{CpMo})_{2}\left(\mu, \eta^{6}: \eta^{6}-\mathrm{P}_{6}\right)\right]$ (Scheme 1c), but they are a bit shorter than the closest $\mathrm{Hg}-\mathrm{P}$ dis-

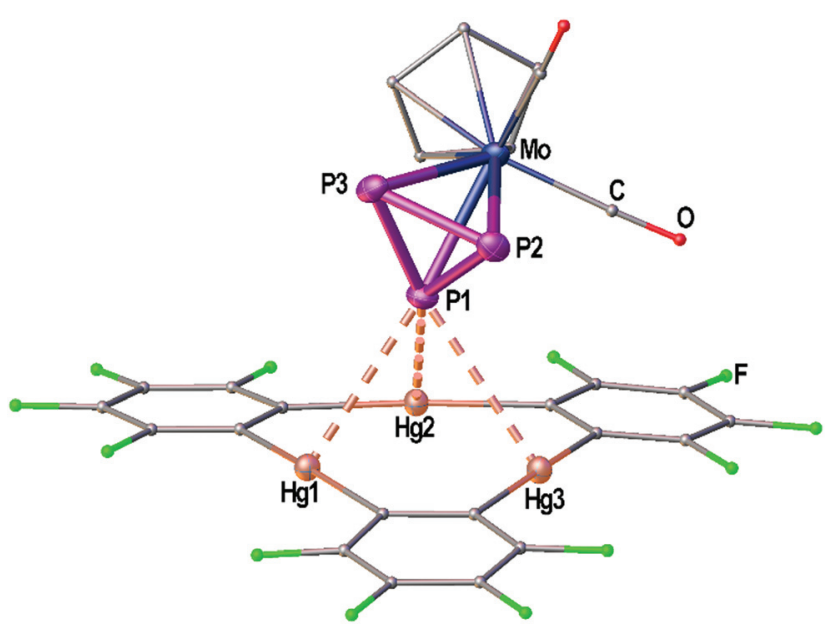

Fig. 1 Solid state structure of compound the adduct [(1).(2)]. Selected bond lengths [Å]: Hg1-P1 3.21821(9), Hg2-P1 3.19349(7), Hg3-P1 3.25262(6), P1-P2 2.140(2), P1-P3 2.145(2), P2-P3 2.147(3); interplanar angle $\mathrm{P}_{3}$ plane $-\mathrm{Hg}_{3}$ plane $=65.43(7)^{\circ}$. Ellipsoids are drawn at $50 \%$ probability. $\mathrm{H}$ atoms are omitted and $\mathrm{C}, \mathrm{F}$ and $\mathrm{O}$ atoms are represented as small spheres for clarity.
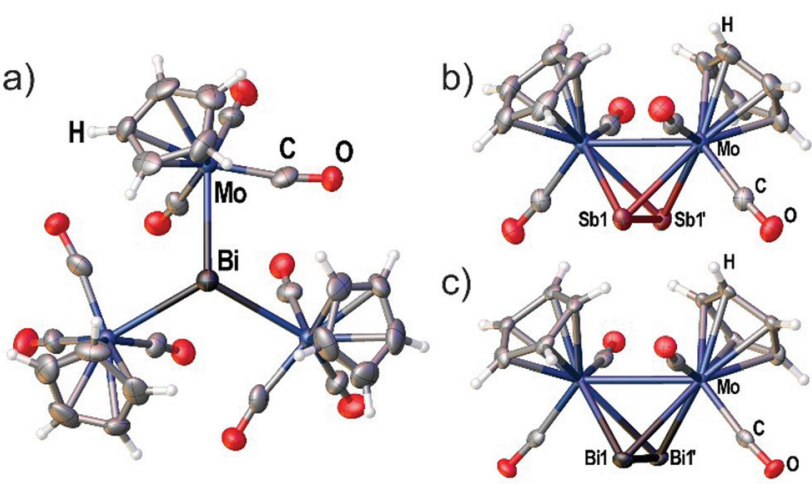

Fig. 2 (a) Crystal structure of $\left[\left\{\mathrm{CpMo}(\mathrm{CO})_{3}\right\}_{3} \mathrm{Bi}\right]$ (4) with viewing direction along the threefold symmetry axis. (b) Crystal structure of the $\mathrm{Sb}_{2}$ complex $3 \mathrm{c}$. (c) Crystal structure of the $\mathrm{Bi}_{2}$ complex $3 \mathrm{~d}$. Selected bond lengths $[\AA \AA]$ and angles $\left[^{\circ}\right]$ : 4: $\mathrm{Mo}-\mathrm{Bi}$ 3.014(3), angle $\mathrm{Mo}-\mathrm{Bi}-\mathrm{Mo}=$ 113.50(5) ${ }^{\circ}$. 3c: Mo1-Mo1' 3.1183(10), Sb1-Sb1' 2.6871(7). 3d: Mo1-Mo1' $3.1378(13)$, Bi1-Bi1' 2.8580 (7). Ellipsoids are drawn at $50 \%$ probability for $3 \mathrm{c}, \mathrm{d}$ and $30 \%$ probability for 4 .

tance that was observed for 1 and $\left[\mathrm{Cp} * \mathrm{Fe}\left(\eta^{5}-\mathrm{P}_{5}\right)\right](3.2878(9) \AA$, Scheme 1d). The angle enclosed between the $\mathrm{P}_{3}$ plane and the $\mathrm{Hg}_{3}$ plane measures $65.43(7)^{\circ}$. The $\mathrm{P}-\mathrm{P}$ bonds show uniform lengths of $2.144(2) \AA$ comparable to the free complex $2 .^{24}$ No $\mathrm{Cp}-\mathrm{Hg}$ contacts are present.

Crystal structures of the $\mathrm{Sb}_{2}$ complex $3 \mathrm{c}$, the $\mathrm{Bi}_{2}$ complex $3 \mathrm{~d}$ and the starting material $\left[\left\{\mathrm{CPMo}(\mathrm{CO})_{3}\right\}_{3} \mathrm{Bi}\right](4)$

Although the synthesis of the $\mathrm{Bi}_{2}$ complex $\mathbf{3 d}$ was already reported in 1988 the solid state structure was only described of a derivative bearing one methyl group on each $\mathrm{Cp}$ ligand. ${ }^{25,26}$ During our investigations we were able to determine the solid state structures of $\mathbf{3 d}$ and of the starting material $\mathbf{4}$ shown in Fig. 2(a) and (c). The synthesis and X-ray structure of the analogous $\mathrm{Sb}_{2}$ complex $3 \mathrm{c}$ was reported ${ }^{27}$ earlier. Moreover, we could structurally characterize a new modification of $3 \mathbf{c}$ by X-ray analysis (see Fig. 2(b)).

The new modification of $3 \mathbf{c}$ crystallizes in the trigonal space group $P 3_{2} 21$ with half a complex in the asymmetric unit. The complex is crystallographically completed by a twofold rotation axis. The determined bond lengths are in good agreement with the previously determined structure (Mo-Mo 3.114(1) A, Sb-Sb 2.678(1) A).

The $\mathrm{Bi}_{2}$ complex $\mathbf{3 d}$ (see Fig. $2(\mathrm{c})$ ) crystallizes in the monoclinic space group $C 2 / c$ with half of the complex in the asymmetric unit. The Mo-Mo bond as well as the Bi-Bi bond is bisected by the twofold rotation axis. The $\mathrm{Bi}-\mathrm{Bi}$ bond length of 2.8580(7) $\AA$ is very comparable to the 2.838(1) $\AA$ found for $\left[\left\{\left(\eta^{5}-\mathrm{C}_{5} \mathrm{H}_{4} \mathrm{Me}\right) \mathrm{Mo}(\mathrm{CO})_{2}\right\}_{2}\left(\mu, \eta^{2}: \eta^{2}-\mathrm{Bi}_{2}\right)\right] .^{25,26}$

Compound 4 crystallizes in the trigonal space group $P 31 \mathrm{c}$ with the central $\mathrm{Bi}$ atom situated on the threefold rotation axis (see Fig. 2a) showing a Mo-Bi bond length of 3.014(3) A. The bonding environment around $\mathrm{Bi}$ is best described as trigonal pyramidal with the three Mo-Bi-Mo angles summing up to $340.50(5)^{\circ}$. 
a)

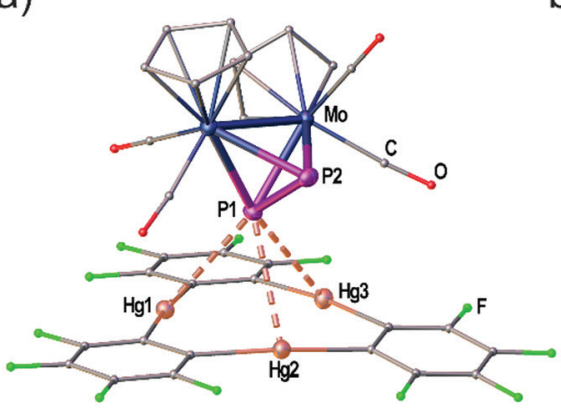

b)

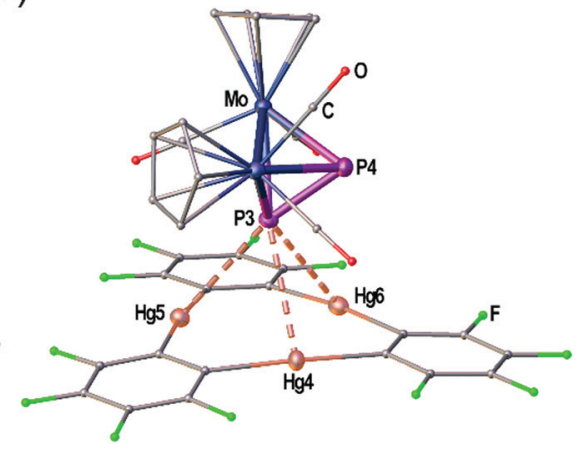

c)

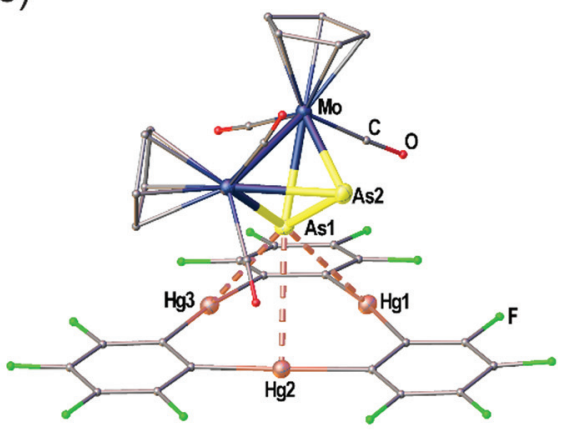

Fig. 3 Independent molecules A (a) and B (b) found in the solid state structure of the adduct [(1).(3a)]. (c) Crystal structure of the adduct [(1).(3b)]. Selected bond lengths [Å]: [(1).(3a)]: Hg1-P1 3.1040(2), Hg1-P2 3.3369(2), Hg1-P3 3.1953(2), Hg4-P3 3.3557(2), Hg5-P3 3.1609(2), Hg6-P3 3.2299(2), P1-P2 2.0883(1), P3-P4 2.0948(1). [(1).(3b)]: Hg1-As1 3.2702(2), Hg2-As1 3.3259(1), Hg3-As1 3.3788(2), As1-As2 2.3162(1). Angles of E2 dumbbells to $\mathrm{Hg}_{3}$ plane: $\mathrm{P} 1 \mathrm{P} 2-\mathrm{Hg} 1 \mathrm{Hg} 2 \mathrm{Hg} 3$ 36.33(1) ${ }^{\circ}$, P3P4-Hg4Hg5Hg6 38.05(1) ${ }^{\circ}$, As1As2-Hg1Hg2Hg3 37.00(1) ${ }^{\circ}$. Ellipsoids are drawn at 50\% probability. $\mathrm{H}$ atoms are omitted and $\mathrm{C}, \mathrm{F}$ and $\mathrm{O}$ atoms are represented as small spheres for clarity.

a)

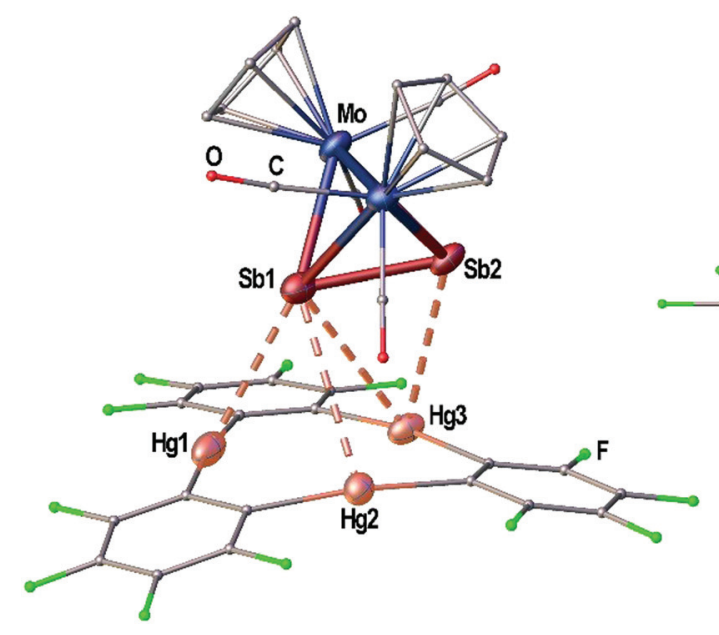

b)

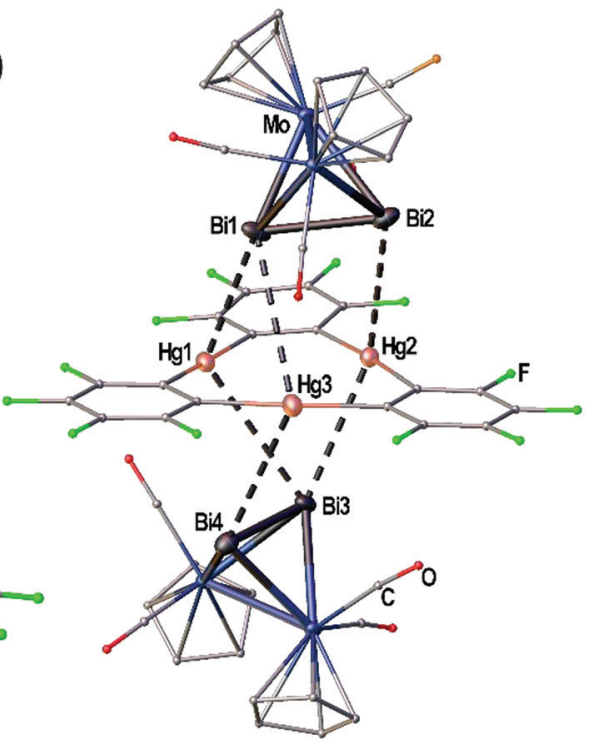

Fig. 4 (a) Solid state structure of the adduct [(1).(3c)]. (b) Solid state structure of the adduct [(1).(3d) 2 ]. Selected bond lengths [Å]: [(1).(3c)]: Hg1-Sb1 3.4336(1), Hg2-Sb1 3.8621(1), Hg3-Sb1 3.7879(2), Hg3-Sb2 3.5222(1), Sb1-Sb2 2.6914(1). [(1).(3d) 2]: Hg1-Bi1 3.4859(1), Hg2-Bi2 3.6370(1), Hg3-Bi1 4.0481(2), Bi1-Bi2 2.8479(1), Hg1-Bi3 3.9046(1), Hg2-Bi3 3.5888(1), Hg3-Bi4 3.7827(1), Bi3-Bi4 2.8537(1). Ellipsoids are drawn at 50\% probability. H

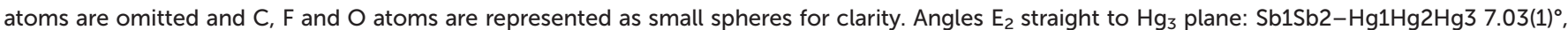
Bi1Bi2- Hg1Hg2Hg3 5.72(1) ${ }^{\circ}, \mathrm{Bi3} 3 i 4-\mathrm{Hg} 1 \mathrm{Hg} 2 \mathrm{Hg} 32.50(1)^{\circ}$.

\section{Structural characterization of the adducts formed from 1 and} the $\mathrm{E}_{2}$ complexes $3 \mathrm{a}-\mathrm{d}$

The adduct $[(\mathbf{1}) \cdot(\mathbf{3 a})]$ crystallizes in the triclinic space group $P \overline{1}$ with two independent formula units [(1).(3a)] in the asymmetric unit shown in Fig. 3(a) and (b). Both molecules of 3a interact with all three $\mathrm{Hg}$ atoms of the Lewis acid 1 via one $\mathrm{P}$ atom which is situated above the center of $\mathbf{1}$ while the other $\mathrm{P}$ atom shows no $\mathrm{Hg}$...P contacts. The resulting $\mathrm{Hg}-\mathrm{P}$ distances lie in the range of 3.10401(15)-3.3557(2) A. The P-P bond lengths are not affected in comparison to free $3 \mathbf{a}(2.079(2) \AA)^{28}$ by the coordination. The angles between the direction of the
$\mathrm{P}_{2}$ dumbbell and the $\mathrm{Hg}_{3}$ plane measure $36.33(1)^{\circ}(\mathrm{P} 1-\mathrm{P} 2)$ and 38.05(1) ${ }^{\circ}$ (P3-P4), respectively.

When looking at the $\mathrm{As}_{2}$ complex $\mathbf{3 b}$ and its interaction with 1 in the solid state shown in Fig. 3(c) it can be noted that the assembly in the adduct $[(\mathbf{1}) \cdot(\mathbf{3 b})]$ is very similar to the $\mathrm{P}_{2}$ complex 3a. This observation was very surprising since we previously observed a distinctly different assembly of cyclo- $\mathrm{P}_{5}$ and cyclo-As ${ }_{5}$ ligands with 1 (see Scheme 1(d) and (e)). The compound $[(\mathbf{1}) \cdot(3 \mathbf{b})]$ crystallizes in a different unit cell (but same space group $P \overline{1})$ than $[(\mathbf{1}) \cdot(\mathbf{3 a})]$ containing only one formula unit in the asymmetric unit. The $\mathrm{As}_{2}$ complex $\mathbf{3 b}$ is interacting with all three $\mathrm{Hg}$ atoms of the Lewis acid 1 via one As atom 
a)

while the second As atom does not show any $\mathrm{Hg}$...As contacts. The resulting $\mathrm{Hg}-\mathrm{As}$ distances lie in the range of 3.27021(13)3.37875(13) $\AA$ and are well within the sum of the vdW radii for $\mathrm{Hg}$ and As (3.7 $\AA)$. The As-As bond length is 2.31607(10) $\AA$ long which is essentially unchanged to free $3 \mathbf{b}(2.305(3) \AA) .{ }^{29}$ The angle enclosed by the $\mathrm{As}_{2}$ dumbbell and the $\mathrm{Hg}_{3}$ plane (37.00(1) $)^{\circ}$ also compares very well to the analogous $\mathrm{P}_{2}$ adduct.

When the $\mathrm{Sb}_{2}$ complex $3 \mathbf{c}$ is allowed to react with the Lewis acid 1 two sorts of crystals (orange and red) are formed from the same solution. Single crystal X-ray diffraction analysis revealed that the orange crystals consist of the equimolar adduct of $\mathbf{1}$ and 3c [(1).(3c)] depicted in Fig. $4 \mathrm{a}$. For $\mathrm{E}=\mathrm{Sb}$, the assembly of the $\mathrm{Mo}_{2} \mathrm{E}_{2}$ complex is different from $\mathrm{E}=\mathrm{P}$, As. The most apparent distinction is the angle enclosed by the $\mathrm{E}_{2}$ dumbbell and the $\mathrm{Hg}_{3}$ plane in [(1).(3c)] which measures only $7.03(1)^{\circ}$. Although Sb1 is also situated above the center of 1 the resulting $\mathrm{Hg}-\mathrm{Sb}$ distances differ significantly. The shortest distance is observed for Hg1-Sb1 with 3.4336(1) A while the distances to $\mathrm{Hg} 2$ and $\mathrm{Hg} 3$ are almost at the edge of vdW contacts (3.9 ̊). The observed arrangement of $\mathbf{1}$ and 3c shows one additional $\mathrm{Hg}-\mathrm{Sb}$ contact between $\mathrm{Sb} 2$ and $\mathrm{Hg} 3$ with 3.5222(1) $\AA$ and can be described as a side-on coordination of the $\mathrm{Sb}-\mathrm{Sb}$ bond to Hg3. The Sb-Sb bond length of 2.6914(1) $\AA$ is essentially unchanged compared to free $3 \mathbf{c}$ (vide supra). ${ }^{27} \mathrm{X}$-ray analysis of the red crystals from the same reaction consist of the adduct $\left[(\mathbf{1})_{2} \cdot(\mathbf{3 c})\right]$ where one $\mathrm{Sb}_{2}$ complex $3 \mathbf{c}$ is surrounded by two molecules of the Lewis acid 1 depicted in Fig. 5(a). The Sb atom Sb1 shows only one contact to Hg1 with 3.5283(9) A. The adduct $\left[(\mathbf{1})_{2} \cdot(\mathbf{3 c})\right]$ crystallizes in the monoclinic space group $P 2 / n$. The twofold rotation axis bisects the Mo-Mo bond as well as the $\mathrm{Sb}-\mathrm{Sb}$ bond of $\mathbf{3 c}$ (see Fig. $5 \mathrm{~b}$ ). The angle enclosed by both $\mathrm{Hg}_{3}$ planes amounts to $53.45(1)^{\circ}$. The Sb1-Sb1' bond length of $2.6863(13) \AA$ is consistently unchanged compared to free $3 \mathbf{c}$.

When the reactivity of the $\mathrm{Bi}_{2}$ complex $\mathbf{3 d}$ towards the Lewis acid 1 was investigated by using different stoichiometries,

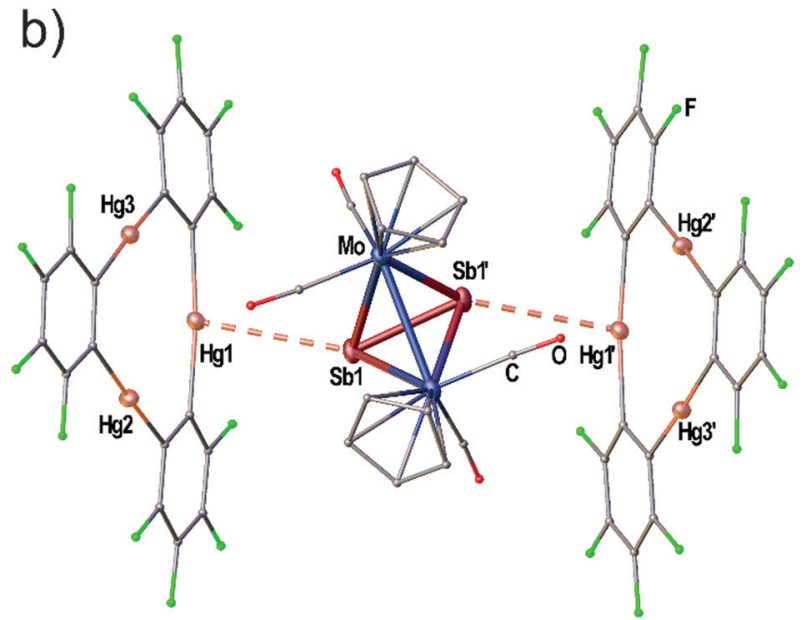

black crystals of pure $\mathbf{3 d}$, colorless crystals of pure $\mathbf{1}$ and black crystals of the adduct $\left[(\mathbf{1}) \cdot(\mathbf{3 d})_{2}\right]$ were obtained next to each other from one reaction. Although numerous crystals were mounted it was not possible to identify any adducts of $\mathbf{1}$ and 3d in different molar ratios. The solid state structure of $\left[(\mathbf{1}) \cdot(\mathbf{3 d})_{2}\right]$ is depicted in Fig. 4(b). The compound crystallizes in the triclinic space group $P \overline{1}$ with two units of $\mathbf{3 d}$ interacting with one molecule of the Lewis acid $\mathbf{1}$ from both sides via both $\mathrm{Bi}$ atoms in the asymmetric unit. The Bi-Bi dumbbells are arranged almost parallel to the $\mathrm{Hg}_{3}$ plane with enclosed angles of $2.50(1)^{\circ}$ and $5.72(1)^{\circ}$, respectively. The center of 1 is not situated below one of the $\mathrm{Bi}$ atoms but rather the middle of the $\mathrm{Bi}-\mathrm{Bi}$ bonds. The resulting $\mathrm{Hg}-\mathrm{Bi}$ distances vary significantly in the range of $3.48590(8)-4.04806(13) \AA$. The Bi-Bi bond lengths in the adduct $\left[(\mathbf{1}) \cdot(\mathbf{3 d})_{2}\right]$ are essentially identical to the free complex $3 \mathbf{d}$ (vide supra). ${ }^{25,26}$

In order to aid in the rationalization of the observed structural trends for the adducts between $\mathbf{3 a - 3 d}$ and $\mathbf{1}$, their constituent compounds were optimized by density functional theory (DFT) methods. The large computed HOMO-LUMO gaps between 1 and 3a-d of 3.06, 3.00, 2.88, and $2.74 \mathrm{eV}$, respectively, suggest that orbital-based interactions are not likely to be dominant within the pnictogen-mercury bonding found in these adducts. Instead, similar to the related adducts of $\mathbf{1}$ with the cyclo- $\mathrm{P}_{5}$ and cyclo- $\mathrm{As}_{5}$ rings of $\left[\mathrm{Cp}^{*} \mathrm{Fe}\left(\eta^{5}-\mathrm{E}_{5}\right)\right]$ complexes, ${ }^{17}$ electrostatic and dispersion forces are likely to factor strongly in the stabilization of the observed structures. In order to probe the potential role of electrostatic forces in the observed adducts, we inspected the electrostatic potential maps of the constituent complexes shown in Fig. 6 . In both $\mathbf{3 a}$ and $\mathbf{3 b}$, the electrostatic potential surface shows accumulation of negative character both across the length of the E-E bond and at the phosphorus and arsenic termini. For the electrostatic potential map of complex $\mathbf{3 c}$, negative character is preferentially accumulated at the $\mathrm{Sb}-\mathrm{Sb}$ bond, with modest negative character still present at the $\mathrm{Sb}$ termini. Finally, in the electrostatic 


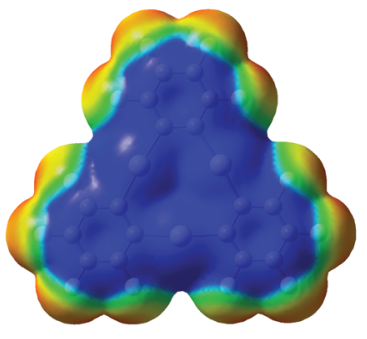

1

$-1.8 \mathrm{e}^{-2}$ a.u. $1.0 \mathrm{e}^{-2}$ a.u.

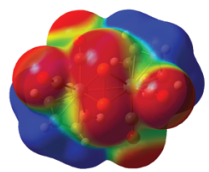

3a

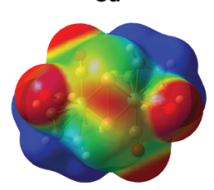

$3 c$

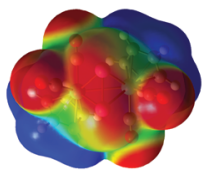

3b

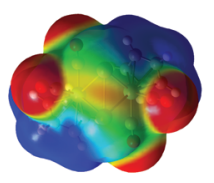

3d
Fig. 6 Electrostatic potential surfaces of compounds 1 and $3 a-d$ (isovalue $=0.004)$. $3 a-d$ : viewing direction along the $C_{2}$ axis of the complexes. $E_{2}$ bonds are in front.

potential map of complex 3d, negative character is expressed almost exclusively at the $\mathrm{Bi}-\mathrm{Bi}$ bond. Taken together, these results suggest that in adducts of $\mathbf{1}$ with $\mathbf{3 a}$ and $\mathbf{3} \mathbf{b}$, the surfaces of the pnictogen termini are complimentary with the positive surface of the mercury centers in $\mathbf{1}$. Complex $\mathbf{3 c}$ appears to be a borderline case, with both residual negative character at the Sb termini and increasing preference for negative character accumulation at the $\mathrm{Sb}-\mathrm{Sb}$ bond possibly accounting for the two distinctly different modes which can be observed in the two adducts of $\mathbf{1}$ and 3c. Finally, the lack of negative character at the Bi termini in complex $\mathbf{3 d}$ accounts for the observed side-on binding mode, as the surface of the $\mathrm{Bi}-\mathrm{Bi}$ bond is most complimentary with the positive character found at the mercury surfaces in $\mathbf{1}$. In an effort to gain further insight into the nature of the $\mathrm{E}-\mathrm{Hg}$ interactions, adducts $[(\mathbf{1}) \cdot(3 \mathbf{a})],[(\mathbf{1}) \cdot(3 \mathbf{b})],\left[(\mathbf{1})_{2} \cdot(\mathbf{3 c})\right],[(\mathbf{1}) \cdot(\mathbf{3 c})]$, and $\left[(\mathbf{1}) \cdot(\mathbf{3 d})_{2}\right]$ were subjected to QTAIM ${ }^{30}$ analysis at their crystal structure geometries (see ESI† for details). In all cases, bond critical points (BCPs) were found between the pnictogen atoms of $\mathbf{3 a - d}$ and the mercury atoms of $\mathbf{1}$. Additional intermolecular BCPs were found between the oxygen atoms of the carbonyl ligands of $\mathbf{3 a}-\mathbf{d}$ and the mercury and carbon atoms of $\mathbf{1}$. Inspection of the features of the electron density distribution function $(\rho(r))$ at the intermolecular BCPs found that similar to the previously observed adducts of 1 with the cyclo- $\mathrm{P}_{5}$ and cyclo- $\mathrm{As}_{5}$ rings of $\left[\mathrm{Cp}{ }^{*} \mathrm{Fe}\left(\eta^{5}-\mathrm{E}_{5}\right)\right]$ complexes, electrostatic and dispersion forces predominate in the adducts of $\mathbf{3 a - d}$ with $\mathbf{1}$.

\section{Structural characterization of the adduct $\left[(1)_{2} \cdot(5)\right]$ and the ' $\mathrm{Cr}_{4} \mathrm{As}_{5}$ ' cluster $\mathbf{5}$}

The Cr-As cluster $\mathbf{5}$ was characterized by chance when $\left[(\mathrm{CpCr})_{2}\left(\mu, \eta^{5}: \eta^{5}-\mathrm{As}_{5}\right)\right]^{31}$ was reacted with 1 . The reaction conducted at room temperature resulted in the formation of amorphous black powder which could not be further characterized and a few dark green crystals of the adduct $\left[(\mathbf{1})_{2} \cdot(\mathbf{5})\right]$. The solid state structure of $\left[(\mathbf{1})_{2} \cdot(\mathbf{5})\right]$ is depicted in Fig. 7(a) showing the unprecedented ' $\mathrm{Cr}_{4} \mathrm{As}_{5}$ ' cluster 5 surrounded by two molecules of $\mathbf{1}$. The adduct $\left[(\mathbf{1})_{2} \cdot(\mathbf{5})\right]$ crystallizes in the monoclinic space group $C 2 / c$ with the twofold rotation axis running through As3

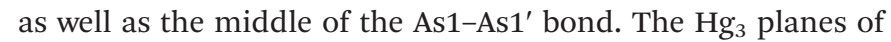
the two molecules of $\mathbf{1}$ are arranged almost perpendicular to each other with an enclosed angle of $87.36(1)^{\circ}$. The assembly results in eight $\mathrm{Hg}$-As distances below the sum of the vdW radii (3.7 ̊). The cluster core of $\mathbf{5}$ depicted in Fig. 7(b) consists of four $\mathrm{Cr}$ atoms in a butterfly structure with $\mathrm{Cr}-\mathrm{Cr}$ bond lengths of 2.9075(1)-3.0134(1) $\AA$, one $\mathrm{As}_{2}$ ligand and one $\mathrm{As}_{3}$ ligand. There is a $\eta^{5}$-bound $\mathrm{Cp}$ ligand on each $\mathrm{Cr}$ atom. Since the Lewis acid 1 generally shows the formation of weakly interacting adducts in combination with pnictogen donors ${ }^{14,17}$ (see above) without changing the geometry or composition of the reactants we assume that the unprecedented cluster 5 was an impurity of the used $\left[(\mathrm{CpCr})_{2}\left(\mu, \eta^{5}: \eta^{5}-\mathrm{As}_{5}\right)\right]$ sample that could not be separated by chromatography before (most probably formed as a byproduct in the thermolytic synthesis of $\left[(\mathrm{CpCr})_{2}\left(\mu, \eta^{5}: \eta^{5}\right.\right.$ $\left.\left.\left.\mathrm{As}_{5}\right)\right]\right) .{ }^{31}$ The cluster could presumably only be characterized by a)

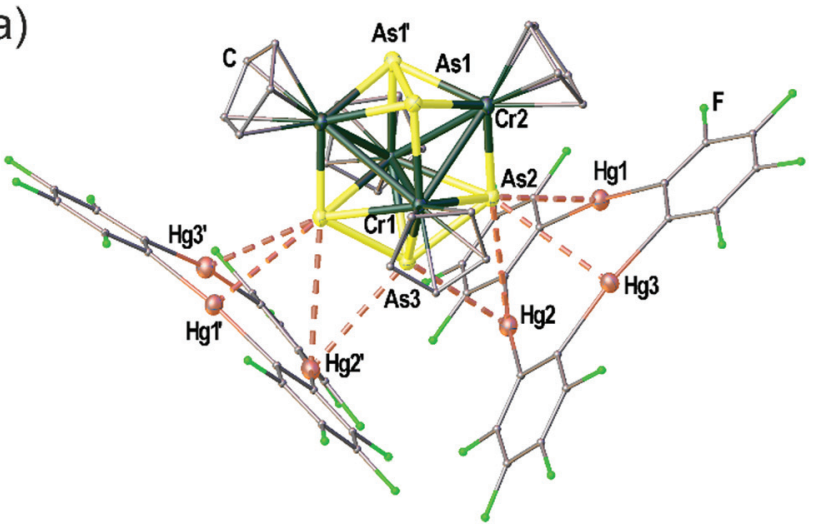

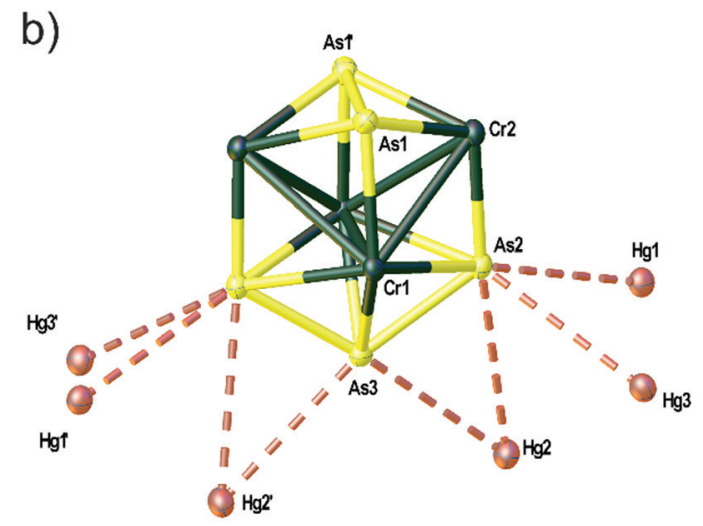

Fig. 7 Solid state structure of the adduct [(1) $\left.)_{2} \cdot(5)\right]$. (a) Representation of the $\mathrm{Cr}$-As cluster 5 coordinated by two molecules of 1. (b) Illustration of the central cluster core of 5 omitting the four $\mathrm{Cp}$ ligands on $\mathrm{Cr}$ and only showing the contacts to the Hg atoms of 1 . Selected bond lengths [Å]: Hg1-As2 2.6863(1), Hg2-As2 3.6066(1), Hg2-As3 3.3557(1), Hg3-As2 3.3944(1), As1-As1' 2.4922(1), As2-As3 2.4456(1), Cr1-Cr1' 2.9075(1), Cr1-Cr2 2.9453(1), Cr1-Cr2' 3.0134(1), Cr1-As1 2.5067(1), Cr1-As2 2.5899(1), Cr1-As2' 2.5698(1), Cr1-As3 2.4683(1), Cr2-As1 2.4450(1), Cr2-As1' 2.4380(1), $\mathrm{Cr} 2-\mathrm{As} 2$ 2.3604(1); angle $\mathrm{Hg}_{3}$ plane $-\mathrm{Hg}_{3}$ plane $87.36(1)^{\circ}$. Ellipsoids are drawn at $50 \%$ probability. $\mathrm{H}$ atoms are omitted and $\mathrm{C}, \mathrm{F}$ and $\mathrm{O}$ atoms are represented as small spheres for clarity. 
$\mathrm{X}$-ray diffraction as it crystallizes very well in the adduct with 1 due to the stabilization by several $\mathrm{Hg}$...As contacts in the solid state. Unfortunately, 5 could not be further characterized due to the very low yield of this side-product.

\section{Conclusion}

The presented results demonstrate the facile preparation of adducts starting from the planar Lewis acid $\mathbf{1}$ and polypnictogen complexes. While the interactions of the $\mathrm{Hg}$ atoms of 1 and the pnictogen donors are very weak resulting in dissociation in solution, several contacts below the sum of the vdW radii can be observed in the solid state. Here, the polyphosphorus complexes $2\left(\mathrm{P}_{3}\right)$ and $3 \mathbf{a}\left(\mathrm{P}_{2}\right)$ show interaction of only one $\mathrm{P}$ atom with all three $\mathrm{Hg}$ atoms of $\mathbf{1}$ in accordance with previously described results from reactions of cyclo- $\mathrm{P}_{5}$ and cyclo- $\mathrm{P}_{6}$ complexes with 1. In the series of the $\mathrm{E}_{2}$ complexes 3a-d a significant influence of the pnictogen atom $(\mathrm{E}=$ $\mathrm{P}, \mathrm{As}, \mathrm{Sb}, \mathrm{Bi}$ ) is revealed. While the assembly of the $\mathrm{As}_{2}$ complex $\mathbf{3 b}$ is very similar to its $\mathrm{P}$ analogue, a different mode of aggregation was observed for the $\mathrm{Sb}_{2}$ and $\mathrm{Bi}_{2}$ complexes $3 \mathrm{c}$ and $\mathbf{3 d}$. In case of $\mathbf{3 c}$ the formation of two adducts with $\mathbf{1}$ was detected. Therein, 3c shows two distinctly different coordination modes towards the planar Lewis acid $\mathbf{1}$. The $\mathrm{Sb}_{2}$ ligand either shows a side-on arrangement towards one molecule of $\mathbf{1}$ or an end-on coordination of both $\mathrm{Sb}$ atoms towards two independent molecules of $\mathbf{1}$. In contrast, the $\mathrm{Bi}_{2}$ complex $\mathbf{3} \mathbf{d}$ shows an almost parallel alignment of the $\mathrm{Bi}_{2}$ dumbbell situated above the center of the planar Lewis acid $\mathbf{1}$. The isolation of $\left[(\mathbf{1}) \cdot(\mathbf{3 d})_{2}\right]$ does not only represent the first adduct of $\mathbf{1}$ with a Bi based Lewis base, but is also the first follow-up chemistry that has been described for the $\mathrm{Bi}_{2}$ complex $\mathbf{3 d}$. The observed arrangements of the $\mathrm{E}_{2}$ complex series can be well rationalized by analysis of the electrostatic potential maps of the complexes 3a-d. In addition, QTAIM analysis and direct comparison to the previously described adducts of $\mathbf{1}$ and the cyclo- $\mathrm{P}_{5}$ and cyclo-As ${ }_{5}$ ligands of $\left[\mathrm{Cp}^{*} \mathrm{Fe}\left(\eta^{5}-\mathrm{E}_{5}\right)\right]$ complexes suggest that electrostatic and dispersion forces predominate in the adducts of $\mathbf{3 a - d}$ with 1. Finally, the structural characterization of a new modification of the $\mathrm{Sb}_{2}$ complex $\left[\left\{\mathrm{CpMo}(\mathrm{CO})_{2}\right\}_{2}\left(\mu, \eta^{2}: \eta^{2}-\mathrm{Sb}_{2}\right)\right](3 \mathbf{c})$, the $\mathrm{Bi}_{2}$ complex $\left[\left\{\mathrm{CpMo}(\mathrm{CO})_{2}\right\}_{2}\left(\mu, \eta^{2}: \eta^{2}-\mathrm{Bi}_{2}\right)\right](\mathbf{3 d})$, the starting material $\left[\left\{\mathrm{CpMo}(\mathrm{CO})_{3}\right\}_{3} \mathrm{Bi}\right](\mathbf{4})$, and a novel $\left[(\mathrm{CpCr})_{4} \mathrm{As}_{5}\right]$ cluster $\mathbf{5}$ are presented.

\section{Acknowledgements}

Manfred Zabel is acknowledged for recording the X-ray dataset for 3c. This work was financially supported by the Deutsche Forschungsgemeinschaft, the National Science Foundation (CHE-1300371) and the Welch Foundation (A-1423). Texas A\&M University (Arthur E. Martell Chair of Chemistry) and the Laboratory for Molecular Simulation at Texas A\&M University (computational resources) are gratefully acknowledged.

\section{Notes and references}

1 B. L. Schottel, H. T. Chifotides and K. R. Dunbar, Chem. Soc. Rev., 2008, 37, 68-83.

2 B. P. Hay and V. S. Bryantsev, Chem. Commun., 2008, 24172428.

3 J. F. Stoddart, Chem. Soc. Rev., 2009, 38, 1802-1820.

4 M. A. Omary, R. M. Kassab, M. R. Haneline, O. Elbjeirami and F. P. Gabbaï, Inorg. Chem., 2003, 42, 2176-2178.

5 P. Sartori and A. Golloch, Chem. Ber., 1968, 101, 20042009.

6 M. R. Haneline, R. E. Taylor and F. P. Gabbaï, Chem. - Eur. J., 2003, 9, 5188-5193.

7 T. J. Taylor, C. N. Burress and F. P. Gabbaï, Organometallics, 2007, 26, 5252-5263.

8 M. Tsunoda and F. P. Gabbaï, J. Am. Chem. Soc., 2000, 122, $8335-8336$

9 C. N. Burress, M. I. Bodine, O. Elbjeirami, J. H. Reibenspies, M. A. Omary and F. P. Gabbaï, Inorg. Chem., 2007, 46, 1388-1395.

10 M. R. Haneline, M. Tsunoda and F. P. Gabbaï, J. Am. Chem. Soc., 2002, 124, 3737-3742.

11 I. A. Tikhonova, D. A. Gribanyov, K. I. Tugashov, F. M. Dolgushin, A. S. Peregudov, D. Y. Antonov, V. I. Rosenberg and V. B. Shur, J. Organomet. Chem., 2010, 695, 1949-1952.

12 M. R. Haneline and F. P. Gabbaï, Angew. Chem., Int. Ed., 2004, 43, 5471-5474.

13 M. C. Ball, D. S. Brown, A. G. Massey and D. A. Wickens, J. Organomet. Chem., 1981, 206, 265-277.

14 M. Fleischmann, C. Heindl, M. Seidl, G. Balázs, A. V. Virovets, E. V. Peresypkina, M. Tsunoda, F. P. Gabbaï and M. Scheer, Angew. Chem., Int. Ed., 2012, 51, 99189921.

15 O. J. Scherer and T. Brück, Angew. Chem., Int. Ed., 1987, 26, 59-59.

16 O. J. Scherer, C. Blath and G. Wolmershäuser, J. Organomet. Chem., 1990, 387, C21-C24.

17 M. Fleischmann, J. S. Jones, F. P. Gabbaï and M. Scheer, Chem. Sci., 2015, 6, 132-139.

18 A. J. Canty and G. B. Deacon, Inorg. Chim. Acta, 1980, 45, L225-L227.

19 S. S. Batsanov, J. Chem. Soc., Dalton Trans., 1998, 15411546.

20 P. Pyykko and M. Straka, Phys. Chem. Chem. Phys., 2000, 2, 2489-2493.

21 K. R. Flower, V. J. Howard, S. Naguthney, R. G. Pritchard, J. E. Warren and A. T. McGown, Inorg. Chem., 2002, 41, 1907-1912.

22 A. F. Holleman, E. Wiberg and N. Wiberg, Lehrbuch der Anorganischen Chemie, Walter de Gruyter, Berlin, 2007.

23 It should be noted, that the CCDC take $1.55 \AA$ as the vdW radius of $\mathrm{Hg}$ (taken from: A. Bondi, J. Phys. Chem., 1964, 68, 441), but this value is probably too small since the authors already mention the fact that it is uncertain how to 
estimate the vdW radius of metals in organometallic compounds.

24 O. J. Scherer, H. Sitzmann and G. Wolmershäuser, Acta Crystallogr., Sect. C: Cryst. Struct. Commun., 1985, 41, 17611763.

25 W. Clegg, N. A. Compton, R. J. Errington and N. C. Norman, Polyhedron, 1988, 7, 2239-2241.

26 W. Clegg, N. A. Compton, R. J. Errington, G. A. Fisher, N. C. Norman and T. B. Marder, J. Chem. Soc., Dalton Trans., 1991, 2887-2895.
27 J. R. Harper and A. L. Rheingold, J. Organomet. Chem., 1990, 390, C36-C38.

28 O. J. Scherer, H. Sitzmann and G. Wolmershäuser, J. Organomet. Chem., 1984, 268, C9-C12.

29 P. J. Sullivan and A. L. Rheingold, Organometallics, 1982, 1, 1547-1549.

30 R. F. W. Bader, Atoms in Molecules: A Quantum Theory, Cambridge University Press, Oxford, UK, 1991.

31 O. J. Scherer, W. Wiedemann and G. Wolmershäuser, J. Organomet. Chem., 1989, 361, C11-C14. 